\title{
Effects of dexamethasone on the TGF- $\beta 1$-induced epithelial-to-mesenchymal transition in human peritoneal mesothelial cells
}

\author{
Yang-Hee Jang ${ }^{1}$, Hyun-Soo Shin ${ }^{1}$, Hack Sun Choi ${ }^{1}$, Eun-Sun Ryu ${ }^{1}$, Mi Jin Kim', Seog Ki Min², \\ Joo-Ho Lee ${ }^{2}$, Hyeon Kook Lee ${ }^{2}$, Kwang-Ho Kim² and Duk-Hee Kang ${ }^{1}$
}

The epithelial-to-mesenchymal transition (EMT) is known to have a role in appropriate embryonic development, the physiological response to injury and pathological events such as organ fibrosis and cancer progression. Glucocorticoid (GC), one of the most commonly used anti-inflammatory drugs, inhibits the deposition of extracellular matrix independent of its anti-inflammatory effect. The EMT of human peritoneal mesothelial cells (HPMCs) is a key mechanism of peritoneal fibrosis; however, it has not yet been investigated whether GC imposes any effect on the EMT of HPMCs. To investigate the therapeutic potential of GC on preserving peritoneal membrane function, we studied the effect of dexamethasone (DEXA), a synthetic GC, on the transforming growth factor- $\beta 1$ (TGF- $\beta 1$ )-induced EMT in HPMCs. As assessed by changes in cell morphology, the expression of epithelial and mesenchymal cell markers (such as E-cadherin, ZO-1 and $\alpha$-SMA, $\alpha$-smooth muscle actin) and cell migration, DEXA inhibited the TGF- $\beta 1$-induced EMT. RU486, a glucocorticoid receptor (GR) antagonist, blocked the effect of DEXA on the TGF- $\beta 1$-induced EMT. Importantly, DEXA also induced the mesenchymal-to-epithelial transition of TGF- $\beta 1$-stimulated HPMCs. The beneficial effect of DEXA on the TGF- $\beta 1$-induced EMT was mediated through the amelioration of ERK and p38 mitogen-activated protein kinase (MAPK) phosphorylation; however, this effect was not related to the TGF- $\beta 1$-induced activation of Smad2/3 signaling. DEXA inhibited glycogen synthase kinase-3 $\beta$ (GSK-3 $\beta$ ) phosphorylation and the Snail upregulation induced by TGF- $\beta 1$, which were also ameliorated by inhibitors of MAPK. In conclusion, this is the first study demonstrating the protective effect of DEXA on the EMT in TGF- $\beta$ 1-stimulated HPMCs by inhibiting MAPK activation, GSK- $3 \beta$ phosphorylation and Snail upregulation.

Laboratory Investigation (2013) 93, 194-206; doi:10.1038/labinvest.2012.166; published online 3 December 2012

KEYWORDS: dexamethasone; epithelial-to-mesenchymal transition; human peritoneal mesothelial cells; peritoneal fibrosis; TGF- $\beta$

The functional and structural deterioration of the peritoneal membrane during peritoneal dialysis (PD) are known to be associated with the phenotypic transition of peritoneal cells. ${ }^{1,2}$ The epithelial-to-mesenchymal transition (EMT) of human peritoneal mesothelial cells (HPMCs) is one of the representative processes of a phenotypic transition, which is characterized by changes in cell morphology, a disruption of tight junctions and a loss of cell polarity with the acquisition of a migratory and invasive phenotype. Cells that have undergone the EMT also acquire the capacity to produce extracellular matrix and a wide spectrum of inflammatory, fibrogenic and angiogenic factors. During the transdifferentiation of epithelial cells, there is a decrease in the expression of a number of epithelial marker proteins including E-cadherin, zonula occludens-1 (ZO-1) and cytokeratin, whereas there is an increase in the synthesis of cytoskeletal proteins such as $\alpha$-SMA, fibronectin and FSP- $1 .{ }^{3,4}$ Because the EMT of HPMCs is regarded as one of the earliest phenomena of peritoneal dysfunction, ${ }^{1,5}$ the molecular mechanisms of the EMT and its regulation are of interest as a potential therapeutic target to ameliorate peritoneal fibrosis. Several studies have demonstrated the

\footnotetext{
${ }^{1}$ Division of Nephrology, Department of Internal Medicine, Ewha Medical Research Center, Ewha Womans University School of Medicine, Seoul, Korea and ${ }^{2}$ Department of Surgery, Ewha Medical Research Center, Ewha Womans University School of Medicine, Seoul, Korea

Correspondence: Dr D-H Kang, MD, PhD, Division of Nephrology, Department of Internal Medicine, Ewha Medical Research Center, Ewha Womans University School of Medicine, 911 Mok-dong Yangcheon-Ku, Seoul 158-710, Korea.

E-mail: dhkang@ewha.ac.kr

Received 2 July 2012; revised 26 September 2012; accepted 18 October 2012
} 
beneficial effect of antifibrotic cytokines, ${ }^{6}$ immunosuppressants ${ }^{7}$ and low-glucose degradation product dialysates ${ }^{8}$ on peritoneal function and morphology by an amelioration of the EMT of HPMCs.

Glucocorticoids (GCs) are a class of steroid hormones that are known to act through the glucocorticoid receptor (GR), a member of the nuclear receptor superfamily. ${ }^{9,10}$ Synthetic GCs are widely used as anti-inflammatory drugs to treat inflammatory disorders, autoimmune diseases and glomerulonephritis. Treatment with dexamethasone (DEXA), a synthetic GC, has been shown to block the production of the extracellular matrix, laminin and fibronectin of epithelial cells; ${ }^{11}$ however, it has also been reported that DEXA promotes renal fibrosis and enhanced plasminogen activator inhibitor-1 (PAI-1) production in renal tubular cells. ${ }^{12}$ The inconsistent effects of GCs on the EMT and organ fibrosis suggest the possibility of differential GC effects in different cells and organs; however, there has been no report as to whether GCs have any role in the peritoneal EMT.

Recently, the downregulation of E-cadherin in epithelial cells was demonstrated to be the key step in initiating phenotype transition and not just a marker of the EMT. ${ }^{13}$ Snail is a major transcriptional repressor of E-cadherin, which is known to be regulated by glycogen synthase kinase-3 $\beta$ (GSK$3 \beta) .{ }^{14}$ There have been no reports as to whether GC imposes any effect on Snail and GSK-3 $\beta$ activation in HPMCs.

In this study, we investigated the effect of DEXA on the EMT of HPMCs by TGF- $\beta 1$, one of the most potent profibrotic cytokines with an elucidation of the signaling mechanism responsible for the effect of TGF- $\beta 1$ and DEXA on the EMT. We also examined whether DEXA imposed any effect on the mesenchymal-to-epithelial transition (MET) of HPMCs and the phenotypic transition of human peritoneal fibroblasts (HPFB). Our studies demonstrate that DEXA ameliorates the EMT and induces the MET by the differential regulation of the TGF- $\beta 1$-induced activation of mitogenactivated protein kinase (MAPK) and Smad2/3 signaling. DEXA also reversed the TGF- $\beta 1$-induced upregulation of Snail via the inactivation of Erk and p38 MAPK with the activation of GSK-3 $\beta$, which resulted in a stabilization of E-cadherin in the HPMCs.

\section{MATERIALS AND METHODS Reagents}

Unless otherwise stated, all chemicals and tissue culture plates were obtained from Sigma-Aldrich (St Louis, MO, USA) and Nunc Labware (Waltham, MA, USA).

\section{Isolation and Maintenance of the HPMCs and HPFBs}

The HPMCs were isolated using a previously published method. ${ }^{6}$ Briefly, a piece of human omentum was obtained from consenting patients undergoing elective abdominal surgery, washed in Hank's balanced salt solution and incubated in a $0.05 \%$ trypsin- $0.02 \%$ EDTA solution for
$20 \mathrm{~min}$ at $37^{\circ} \mathrm{C}$ with continuous agitation. After the incubation period, the suspension was centrifuged at $500 \times g$ for $5 \mathrm{~min}$ at $4{ }^{\circ} \mathrm{C}$, and the cells were cultured in medium 199 supplemented with $10 \% \mathrm{FBS}, 100 \mathrm{U} / \mathrm{ml}$ penicillin, $100 \mu \mathrm{g} / \mathrm{ml}$ streptomycin and $26 \mathrm{mmol} / 1 \mathrm{NaHCO}_{3}$. Half of the medium was exchanged $48 \mathrm{~h}$ after the seeding, and the entire medium was replaced once every 4 days. For the isolation of HPFBs, the remaining tissue after an isolation of HPMCs was transferred to fresh trypsin/EDTA solution and processed further until a homogenous population of HPFBs was obtained. ${ }^{15}$

The HPMCs and HPFBs were identified using phase contrast microscopy according to morphological criteria and using an immunofluorescence technique. ${ }^{6}$ All experiments were performed using cells between the second and fourth passages. The tissue collection was approved by the ethics committee of the Ewha Medical Center (ECT 164-7) and informed consent was obtained from each patient.

\section{Cell Proliferation and the Cytotoxicity Assay}

For measuring the proliferation of the HPMCs, the MTS uptake assay was used. The cells were grown in a 96-well plate and treated with DEXA (from $0.1 \mu \mathrm{m}$ to $1 \mathrm{~mm}$ ) for $48 \mathrm{~h}$. After the addition of $20 \mu \mathrm{l}$ of the MTS reagent and an incubation period of $4 \mathrm{~h}$ in a $5 \% \mathrm{CO}_{2}$ atmosphere at $37^{\circ} \mathrm{C}$, the proliferation of the HPMCs was assessed by reading the absorbance at $490 \mathrm{~nm}$ on a 96-well plate reader (Dynex Revelation, Dynex , Billingshurst, UK). The cytotoxicity of DEXA to the HPMCs was determined by measuring the amount of lactate dehydrogenase (LDH) released into the medium after a $48-\mathrm{h}$ treatment using the LDH cytotoxicity detection kit (Roche, Mannheim, Germany). Each series of data were determined in triplicate.

\section{Cell Migration Assay}

Changes in cell migration were assessed using a transwell migration assay in a Boyden chamber with $8 \mu \mathrm{m}$ pore polyvinylpyrrolidone-free polycarbonate membranes (Neuro Probe, Gaithersburg, MD, USA). ${ }^{16}$ The filters were immersed overnight in $130 \mu \mathrm{g} / \mathrm{ml}$ matrigel $(10 \mu \mathrm{g} / \mathrm{ml} ;$ Becton Dickenson, Franklin Lakes, NJ, USA) in PBS at $4{ }^{\circ} \mathrm{C}$. The HPMCs were seeded onto the top of the transwell filter with the addition of DEXA $(10 \mu \mathrm{M})$ to the lower chamber under serum-free conditions. After $48 \mathrm{~h}$ of incubation with TGF- $\beta$, the filters were fixed with $4 \%$ paraformaldehyde and stained with $1 \%$ crystal violet in PBS. The upper surface of the filter was carefully wiped with a cotton-tipped applicator. Cells that passed through the filter pores and attached to the undersurface of the filter were counted at high-power $(\times 200)$. Each sample was assayed in triplicate in four separate experiments.

\section{Cell Morphology and the Immunofluorescence Analyses of the HPMCs}

Cell morphology was analyzed using an inverted phase contrast microscope (Axiovert 200; Carl Zeiss, Oberkochen, 
Germany), and the images were obtained using a digital camera (AxioCam HRC; Carl Zeiss). For immunofluorescence staining, the cells were washed and fixed in $4 \%$ phosphate-buffered paraformaldehyde for $25 \mathrm{~min}$ at $20^{\circ} \mathrm{C}$ and permeabilized with $1 \%$ Triton X 100 in PBS for $15 \mathrm{~min}$ at $4{ }^{\circ} \mathrm{C}$. After washing with PBS, the cells were treated with $5 \%$ BSA in PBS for $1 \mathrm{~h}$ before being incubating with primary antibodies specific for ZO-1 (Invitrogen, Calsbad, CA, USA) or $\alpha$-SMA (Santa Cruz Biotechnology, Santa Cruz, CA, USA) in $5 \%$ BSA overnight at $4{ }^{\circ} \mathrm{C}$. The cells were then washed with $0.2 \%$ Tween 20 in PBS before being incubating with a goat anti-mouse IgG-FITC-conjugated secondary antibody (Santa Cruz Biotechnology) for $1 \mathrm{~h}$ at room temperature in the dark. The nuclei were counterstained with DAPI, and the cells were visualized using an Axiovert 200 fluorescence microscope with $10 \times 10$ and $20 \times 10$ NA objectives. Digital photographs were obtained using Axiovision 4.3 (Carl Zeiss), and merged images were obtained using Photoshop 7.0 (Adobe Systems, Toronto, ON, Canada).

\section{Western Blotting}

After isolating protein from the cell lysates $(30 \mu \mathrm{g})$, the samples were mixed in a reducing buffer, boiled, resolved on $10 \%$ SDS-PAGE gels, and transferred to a polyvinylidene difluoride membrane (Millipore, Bedford, MA, USA) by electroblotting. The membranes were blocked in 5\% (wt/vol) nonfat milk powder in Tris-buffered saline supplemented with Tween 20 for $30 \mathrm{~min}$ at room temperature. The blots were then incubated in blocking solution with primary antibodies overnight at $4{ }^{\circ} \mathrm{C}$. Mouse monoclonal human E-cadherin (BD Bioscience, Bedford, MA, USA), mouse monoclonal human $\alpha$-SMA, mouse polyclonal human $\beta$-actin (Santa Cruz Biotechnology), goat polyclonal human fibroblast CD34 (Santa Cruz Biotechnology) and goat polyclonal human vimentin (Santa Cruz Biotechnology) were used as the primary antibodies. ERK1/2, p38 MAPK, Smad 2/ 3 and GSK-3 $\beta$ phosphorylation in the HPMCs treated with TGF- $\beta$ and/or DEXA were assessed by western blot analysis using primary antibodies for ERK1/2 (Santa Cruz Biotechnology), phospho-ERK (Santa Cruz Biotechnology), p38 (Santa Cruz Biotechnology), phospho-p38 (Santa Cruz Biotechnology), phospho-Smad2 (Cell Signaling, Danvers, USA), phospho-Smad3 (Cell Signaling), Smad2/3 (Santa Cruz Biotechnology), GSK-3 $\beta$ (Cell Signaling) and phosphoGSK-3 $\beta$ (Cell Signaling). Snail (Cell Signaling), a key transcriptional repressor of E-cadherin, was also evaluated in the HPMCs. After washing the blots with Tris-buffered saline supplemented with Tween 20, the blots were incubated with horseradish peroxidase-conjugated secondary antibodies corresponding to each primary antibody and enhanced using chemiluminescence detection (Santa Cruz Biotechnology). Positive immunoreactive bands were quantified using densitometry and compared with the expression of human $\beta$ actin (Santa Cruz Biotechnology).

\section{Extraction of Total RNA and Real-Time PCR}

After each experiment, total cellular RNA was extracted using TRIzol, and contaminating DNA was removed using RNAase-free DNase. The DNA-free RNA was reverse-transcribed into cDNA using the Superscript First Strand Synthesis system (Life Technologies BRL, Carlsbad, CA, USA). Real-time PCR was performed on the ABI PRISM 7700 Sequence Detection system using SYBR Green I as a double-stranded DNA-specific dye according to the manufacturer's instructions (Applied Biosystems, Foster City, CA, USA). The PCR reaction was performed with $5 \mu \mathrm{l}$ of cDNA, $10 \mu \mathrm{l}$ of SYBR Green PCR master mix, and 5 pM of sense and antisense primers (a final volume of $20 \mu \mathrm{l}$ per reaction). The primer concentrations were determined using preliminary experiments that analyzed the optimal concentrations of each primer. All primers used in the real-time PCR were designed using the Primer Express 2.0 software (Applied Biosystems) and checked for homology using BLAST (Supplementary Table 1). The PCR conditions used were as follows: for E-cadherin, 40 cycles of denaturation at $95^{\circ} \mathrm{C}$ for $15 \mathrm{sec}$, annealing at $60{ }^{\circ} \mathrm{C}$ for $30 \mathrm{sec}$ and a final extension step at $72{ }^{\circ} \mathrm{C}$ for $1 \mathrm{~min}$; for $\alpha$-SMA, 40 cycles of denaturation at $95^{\circ} \mathrm{C}$ for $20 \mathrm{~s}$, annealing at $60^{\circ} \mathrm{C}$ for $30 \mathrm{~s}$ and a final extension step at $72^{\circ} \mathrm{C}$ for $30 \mathrm{~s}$; and for fibronectin and $\beta$-actin, 40 cycles of denaturation at $95^{\circ} \mathrm{C}$ for $30 \mathrm{sec}$, annealing at $60{ }^{\circ} \mathrm{C}$ for $30 \mathrm{sec}$ and a final extension step at $72^{\circ} \mathrm{C}$ for $1 \mathrm{~min}$. At the end of each reaction, a melting curve analysis was performed using one cycle of $95^{\circ} \mathrm{C}$ for $30 \mathrm{~s}$ and $60^{\circ} \mathrm{C}$ for $10 \mathrm{~s}$, with a temperature transition rate of $2{ }^{\circ} \mathrm{C} / \mathrm{min}$ and then ramping to $95^{\circ} \mathrm{C}$. A control without cDNA was run in parallel with each assay. The relative mRNA expression levels of the target genes in each sample were calculated using the comparative CT method. The CT value is the cycle number at which the fluorescence signal is greater than a defined threshold. At least three independent PCR procedures were performed to allow for statistical analyses. The amount of PCR products was normalized with the housekeeping gene $\beta$-actin to determine the relative expression ratios for each mRNA in relation to the control group.

\section{Effect of RU486, PD98059 and SB203589}

To examine whether the effects of DEXA on the TGF- $\beta 1$ induced EMT in the HPMCs were GR-mediated, we used a GR antagonist, RU486 $(2 \mu \mathrm{M})$. The ERK and p38 MAPK blockers, PD98059 $(10 \mu \mathrm{M})$ and SB203589 $(10 \mu \mathrm{M})$, respectively, were also used in experiments to investigate the role of MAPK on the effect of DEXA on the EMT and GSK-3 $\beta$ activation.

\section{siRNA Transfections}

To determine the contribution of Smad2 and Smad3 to the effect of DEXA on the TGF- $\beta$-induced EMT of the HPMCs, we treated the HPMCs with human Smad2 and Smad3 siRNAs obtained from Thermo Scientific (San Diego, CA, USA). The following siRNAs were used: for Smad2, ON-TARGET- 

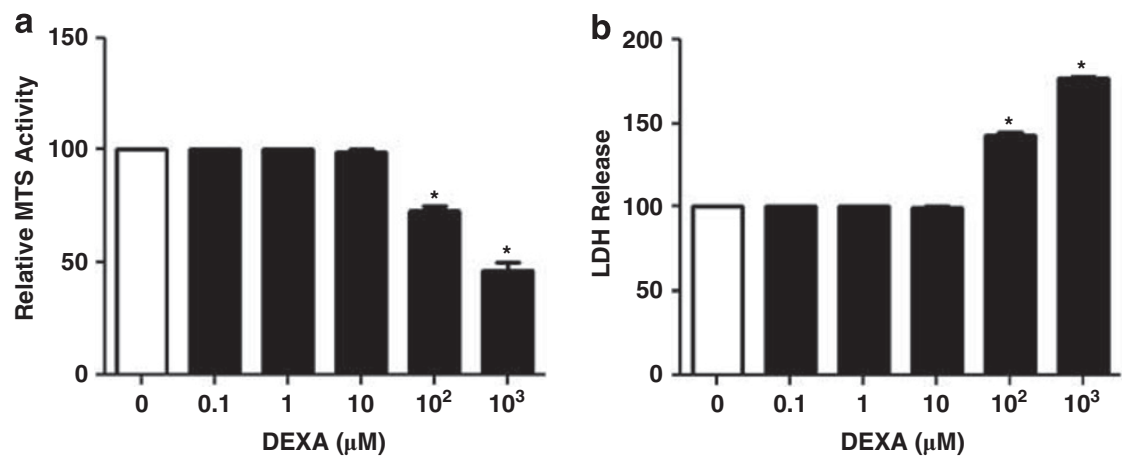

Figure 1 Effects of DEXA on cell proliferation (a) and cytotoxicity (b) in HPMCs. DEXA inhibits the growth of HPMCs in a concentration-dependent manner at $\geq 100 \mu \mathrm{m}$. DEXA also induces LDH release at $\geq 100 \mu \mathrm{m}(n=5) .{ }^{*} P<0.05$ vs $0-10 \mu \mathrm{m}$ of DEXA.
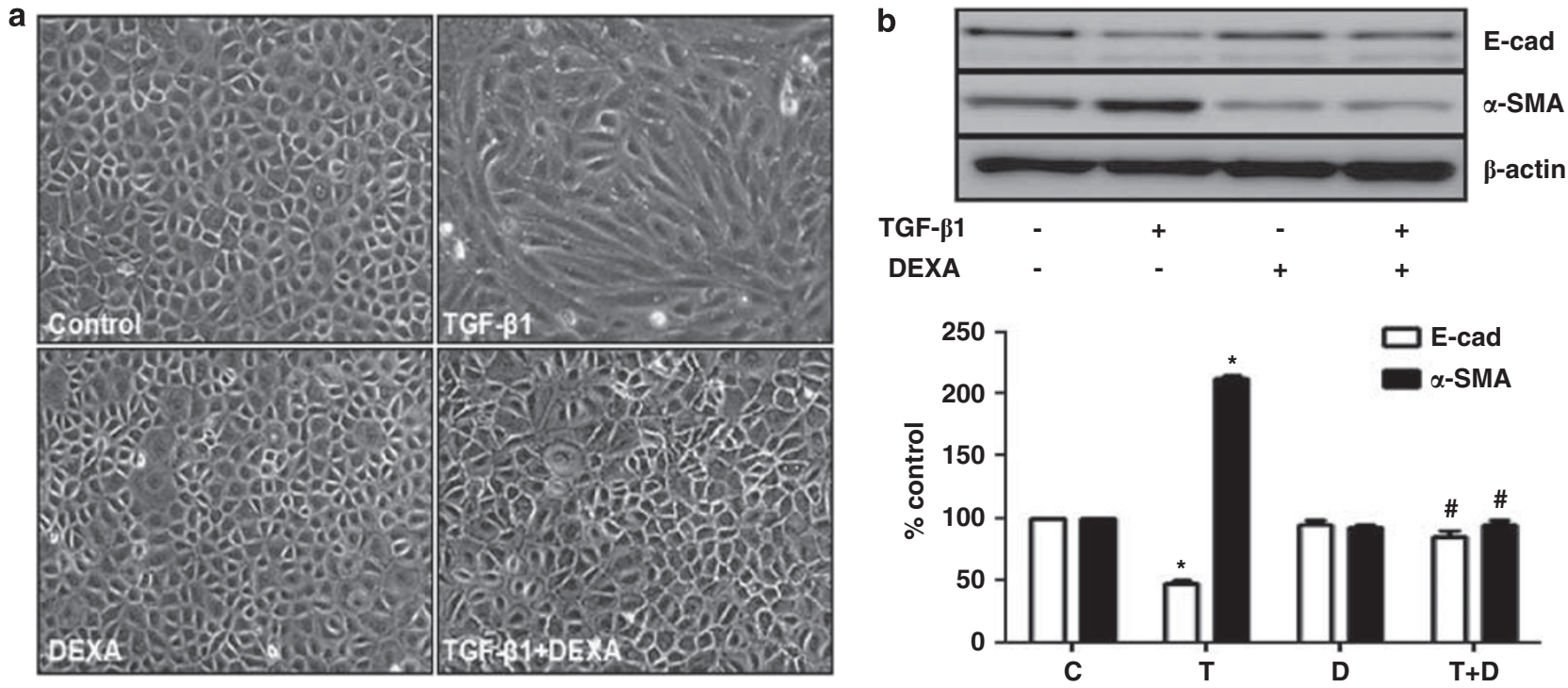

Figure 2 Effect of DEXA on cell morphology (a) and the expression of E-cadherin and $\alpha$-SMA (b) in TGF- $\beta 1$-stimulated HPMC. Phase contrast microscopy reveals elongated, fibroblast-like cells after TGF- $\beta 1(1 \mathrm{ng} / \mathrm{ml})$ stimulation for $48 \mathrm{~h}$, compared with a cuboidal cobble stone appearance for the control HPMCs. DEXA $(10 \mu \mathrm{m})$ ameliorates the morphologic changes of TGF- $\beta 1$-stimulated HPMCs (a, Magnification, $\times 100)$. Representative western blotting with quantitative analyses demonstrating a decrease in the expression of the epithelial cell marker E-cadherin with the acquisition of $\alpha$-SMA in TGF- $\beta 1$-stimulated HPMCs, which was alleviated by DEXA treatment $(n=5)$. C, control; T, TGF- $\beta 1 ; \mathrm{D}, \mathrm{DEXA} .{ }^{*} P<0.05$ vs others, ${ }^{\#} P<0.05$ vs TGF- $\beta 1$.

plus SMARTpool human Smad2 (4087) and for Smad3, ONTARGETplus SMARTpool human Smad3 (4088). The scrambled siRNA control is a nontargeting siRNA pool from Thermo Scientific. For the transfection of the siRNAs, the HPMCs were seeded into six-well plates for $24 \mathrm{~h}$ at $\sim 80 \%$ confluence. The transfections were then performed using Lipofectamine 2000 (Invitrogen) according to the manufacturer's protocol.

\section{Statistical Analyses}

All data are presented as the means \pm s.d. Differences in the various parameters between groups were evaluated using a two-way ANOVA followed by a correction for multiple comparisons. The results were considered significant if the $P$ values were $\leq 0.05$.

\section{RESULTS \\ DEXA Ameliorates the TGF- $\beta 1$-induced EMT of the HPMCs}

To determine the proper concentration of DEXA for the in vitro experiment, we analyzed the effects of DEXA (0.1 $\mu \mathrm{M}-1 \mathrm{~mm}$ ) on cell proliferation and cytotoxicity. There was a concentration-dependent inhibition of cell proliferation with $\geq 100 \mu \mathrm{m}$ DEXA after $48 \mathrm{~h}$ of stimulation. There was no significant cytotoxicity observed in DEXA-stimulated cells with a concentration up to $10 \mu \mathrm{M}$ (Figure 1a and b).

TGF- $\beta 1(1 \mathrm{ng} / \mathrm{ml})$ induced the EMT, as indicated by changes in cell morphology (Figures $2 \mathrm{a}$ and 3 ) and the altered expression of the epithelial markers E-cadherin and ZO-1 and the mesenchymal marker $\alpha$-SMA (Figures $2 \mathrm{~b}$ and 3 ). DEXA $(10 \mu \mathrm{M})$ ameliorated the morphological transition (Figures 2a and 3) and restored the expression of E-cadherin 

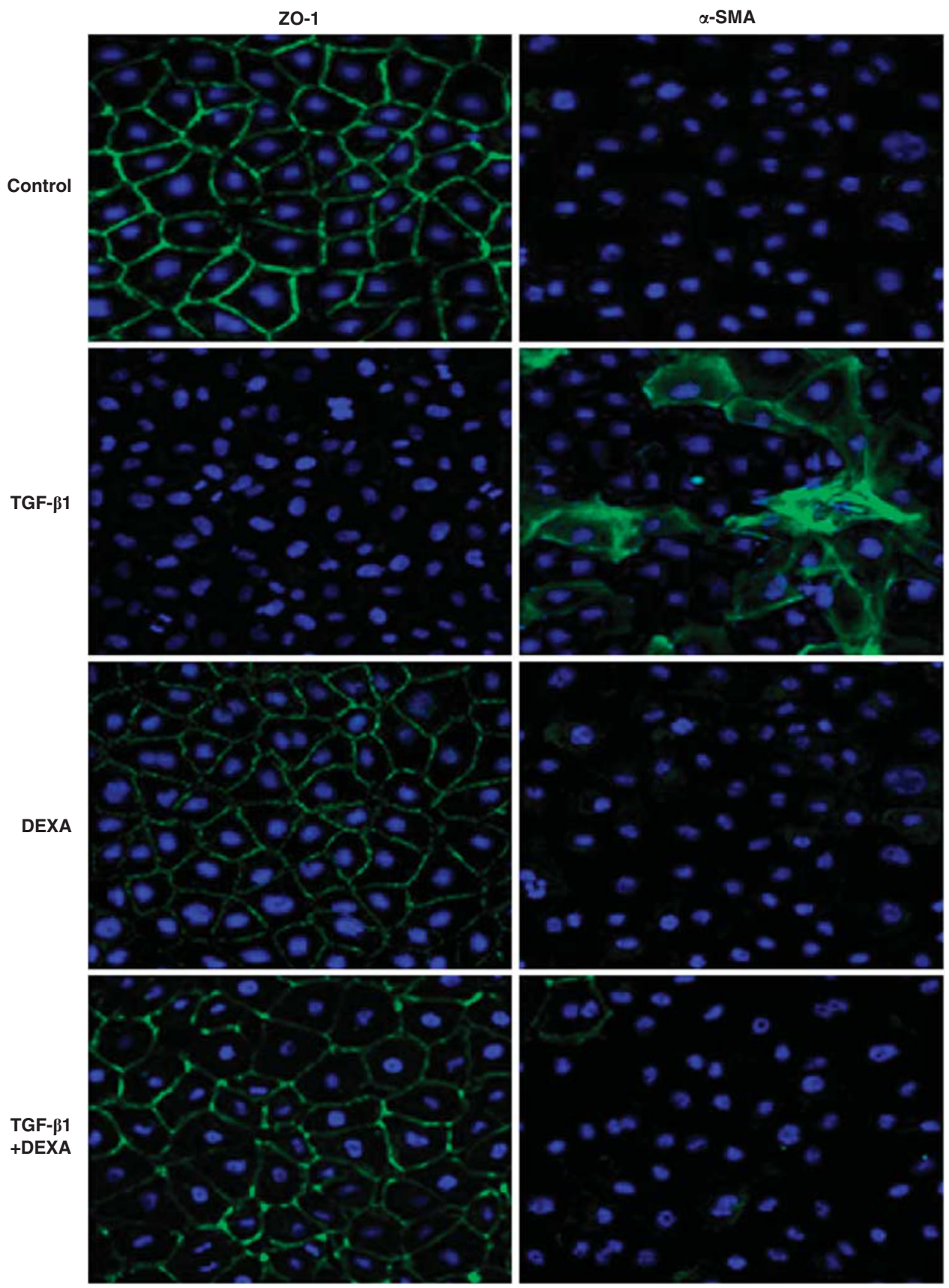

Figure 3 Fluorescence immunocytochemistry for ZO-1 and $\alpha$-SMA in HPMCs. Untreated or DEXA (10 $\mu \mathrm{m}$ )-treated HPMCs display abundant ZO-1 expression with negligible $\alpha$-SMA expression. TGF- $\beta 1$ treatment for $48 \mathrm{~h}$ results in a decrease in ZO- 1 and an increase in $\alpha$-SMA, which are ameliorated with DEXA $(n=7)$. (Magnification, $\times 100)$.

and ZO- 1 in the TGF- $\beta 1$-stimulated HPMCs. DEXA also inhibited the TGF- $\beta 1$-induced acquisition of $\alpha$-SMA expression (Figures $2 \mathrm{~b}$ and 3 ).

The real-time PCR analyses verified the similar results obtained with western blotting and the immunofluorescein staining. TGF- $\beta 1$ downregulated the expression of the E-cadherin gene and induced the de novo expression of the $\alpha$ SMA and fibronectin genes (Figure 4), which were inhibited by DEXA treatment (Figure 4).

\section{RU486 Reverses the Effect of DEXA}

Pretreatment with RU486, a GR antagonist, abolished the beneficial effect of DEXA on the TGF- $\beta 1$-induced EMT (Figure 5a), indicating a GR-mediated effect of DEXA on the EMT.

\section{DEXA Inhibits TGF- $\beta 1$-Induced Cell Migration}

Along with its effect on cell morphology and phenotype, DEXA also ameliorated the increase in cell migration 

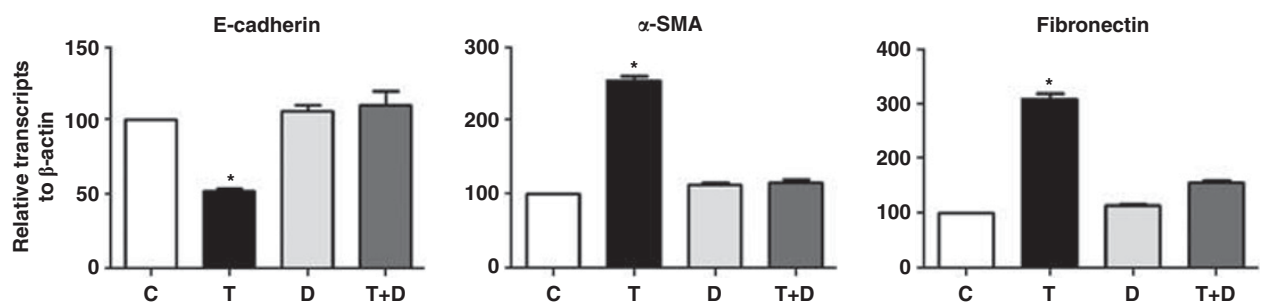

Figure 4 Effect of DEXA on the mRNA expression of E-cadherin, $\alpha$-SMA and fibronectin using real-time PCR. TGF- $\beta 1$ treatment for $24 \mathrm{~h}$ increases the mRNA expression levels of $\alpha$-SMA and fibronectin, whereas reduces the level of E-cadherin mRNA expression, which are alleviated by DEXA (10 $\mu \mathrm{m})$ $(n=5)$. C, control; T, TGF- $\beta 1$; D, DEXA. ${ }^{*} P<0.05$ vs others.
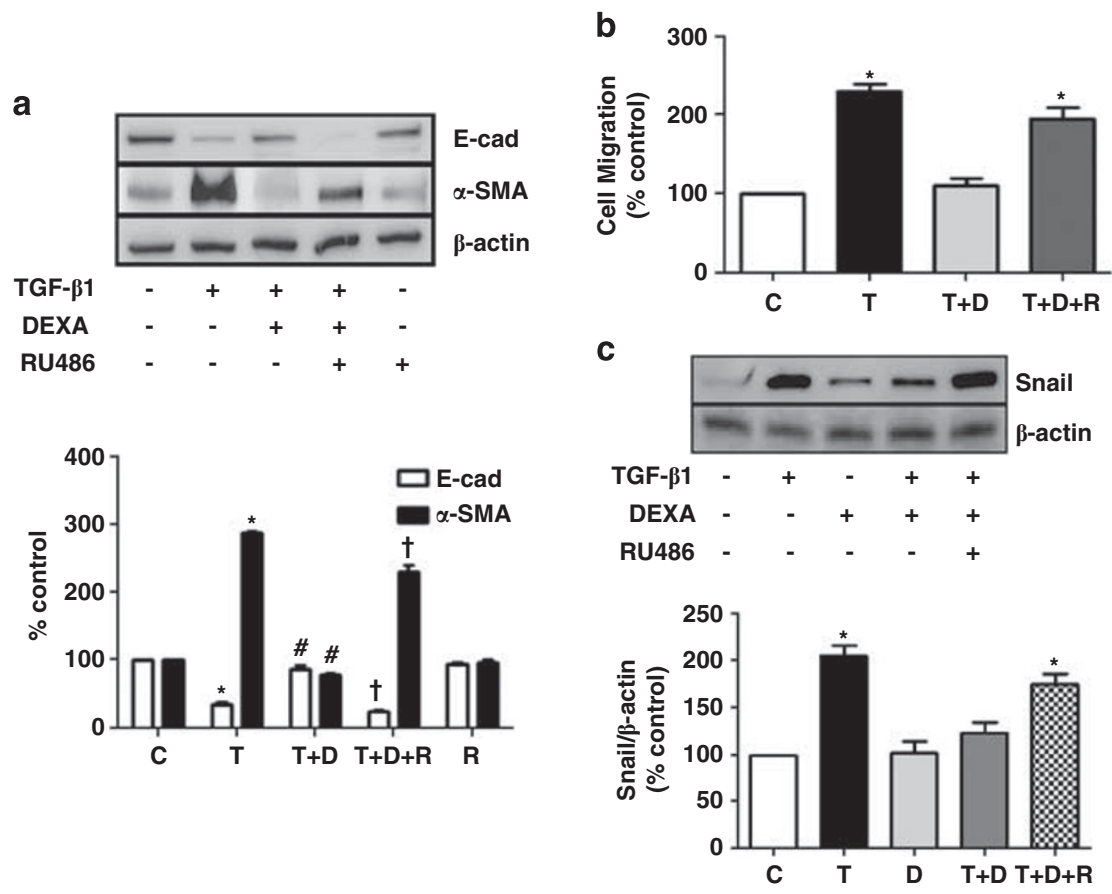

Figure 5 Effect of RU486, a GR antagonist, on the EMT and Snail expression. RU486 ( $2 \mu \mathrm{M})$ ameliorates the effect of DEXA (10 $\mu \mathrm{M})$ on the TGF- $\beta 1$ induced alteration of E-cadherin and $\alpha$-SMA after $48 \mathrm{~h}$ of stimulation. A representative western blot and quantitation are shown ( $n=5$ ) (a). C, control; $\mathrm{T}$, TGF- $\beta 1$; D, DEXA; R, RU486. ${ }^{*} P<0.05$ vs $C, T+D$ and $R,{ }^{*} P<0.05$ vs $T$ and $T+D+R,{ }^{\dagger} P<0.05$ vs $C, T+D$ and $R$. DEXA also inhibits TGF- $\beta 1$-induced cell migration (b) $(n=3)$ and Snail upregulation (c) $(n=5) .{ }^{*} P<0.05$ vs $\mathrm{C}, \mathrm{D}$ and $\mathrm{T}+\mathrm{D}$.

induced by TGF- $\beta 1$ (Figure $5 \mathrm{~b}$ ). A significant increase (twofold) in cell motility was assessed using the transwell migration of TGF- $\beta 1$-stimulated HPMCs, which almost returned to the control level after the DEXA treatment. The inhibiting effect of DEXA on the TGF- $\beta 1$-induced migration of the HPMCs was blocked by a pretreatment with RU486.

\section{DEXA Ameliorates TGF- $\beta 1$-Induced Snail Expression}

TGF- $\beta 1$ upregulated Snail expression in the HPMCs, which was ameliorated by DEXA. RU486 blocked the effect of DEXA on TGF- $\beta 1$-induced Snail (Figure $5 \mathrm{c}$ ).

\section{DEXA Reverses the EMT or induces the MET in TGF- $\beta 1$ - Stimulated HPMCs}

Interestingly, the EMT of the HPMCs that was induced by TGF- $\beta 1$ stimulation for $48 \mathrm{~h}$ was partially reversed by the removal of TGF- $\beta 1$ (Figure $6 \mathrm{a}$ and $\mathrm{b}$ ). The addition of DEXA coupled with the removal of TGF- $\beta 1$ further restored the cell morphology with a partial reversal of the altered expression levels of E-cadherin and $\alpha$-SMA (Figure $6 \mathrm{a}$ and $\mathrm{b}$ ), suggesting DEXA actually induces the MET of TGF- $\beta 1$-stimulated HPMCs. RU486 abolished the effect of DEXA on the MET (Figure 6).

\section{ERK1/2 and p38 MAPK Activation is Responsible for the Effect of DEXA on the TGF- $\beta 1$-Induced EMT}

To further understand the mechanisms responsible for the TGF- $\beta 1$-induced EMT in the HPMCs, we investigated the activation of the ERK1/2 and p38 MAPK signaling pathway by TGF- $\beta 1$ and/or DEXA. TGF- $\beta 1$ activated ERK1/2 and p38 MAPK in the HPMCs after 5 min with a secondary peak at $24 \mathrm{~h}$ (Supplementary Figure 1). Both an ERK1/2 inhibitor 

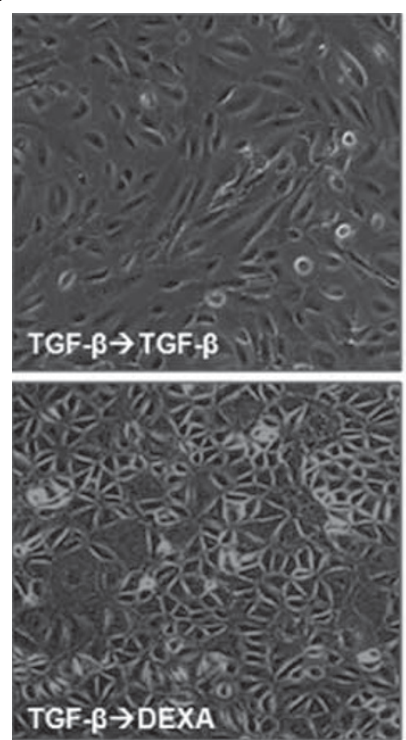
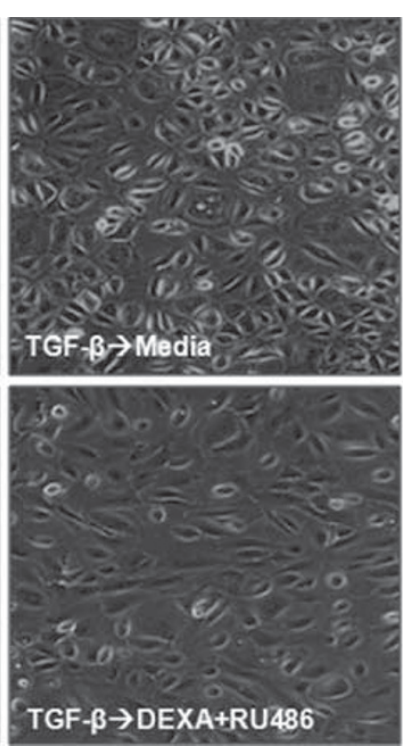

b
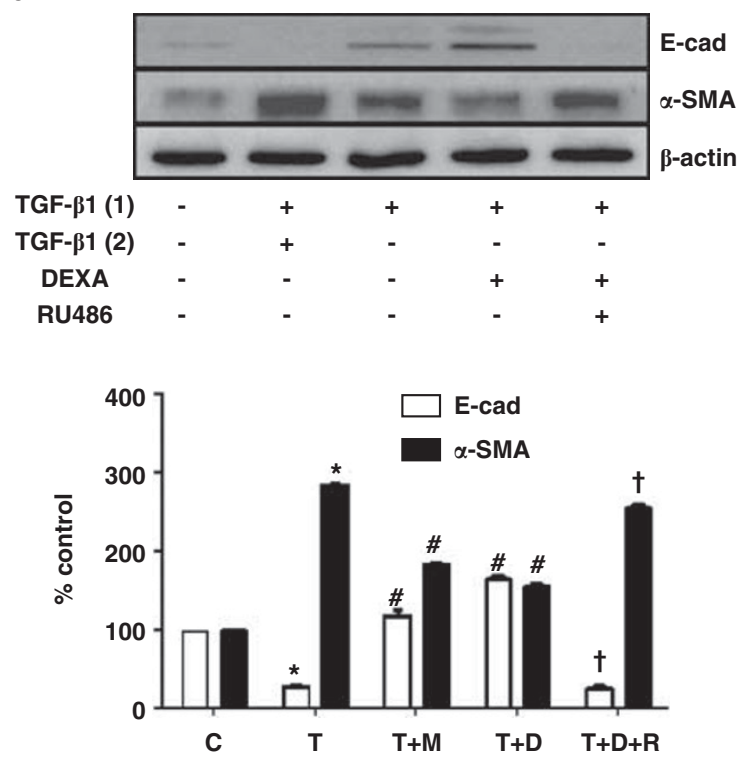

Figure 6 Reversibility of the TGF- $\beta 1$-induced EMT and the effect of DEXA on the MET in HPMCs. The removal of TGF- $\beta 1$ after $48 \mathrm{~h}$ of stimulation and a subsequent incubation with control media for an additional $48 \mathrm{~h}$ results in a partial reversal of cell morphology, compared with continuous stimulation with TGF- $\beta 1$ for $96 \mathrm{~h}$ (a). The removal of TGF- $\beta 1$ with the addition of DEXA further recovers the morphology, which is blocked by RU486 (a,

Magnification, $\times 100)$. A representative western blot and quantitation (b) are shown. TGF- $\beta 1$ (1) and TGF- $\beta 1$ (2) denote the first and second $48 \mathrm{~h}$ of stimulation with TGF- $\beta$, respectively $(N=5)$. C, control; T, TGF- $\beta 1 ; T+M$, TGF- $\beta 1$ and media; T $+D, T$ TGF- $\beta 1$ and DEXA; T $+D+R, T G F-\beta 1, D E X A$ and RU486. ${ }^{*} P<0.05$ vs $C, T+M$ and $T+D,{ }^{*} P<0.05$ vs others, ${ }^{\dagger} P<0.05$ vs $C, T+M$ and $T+D$.
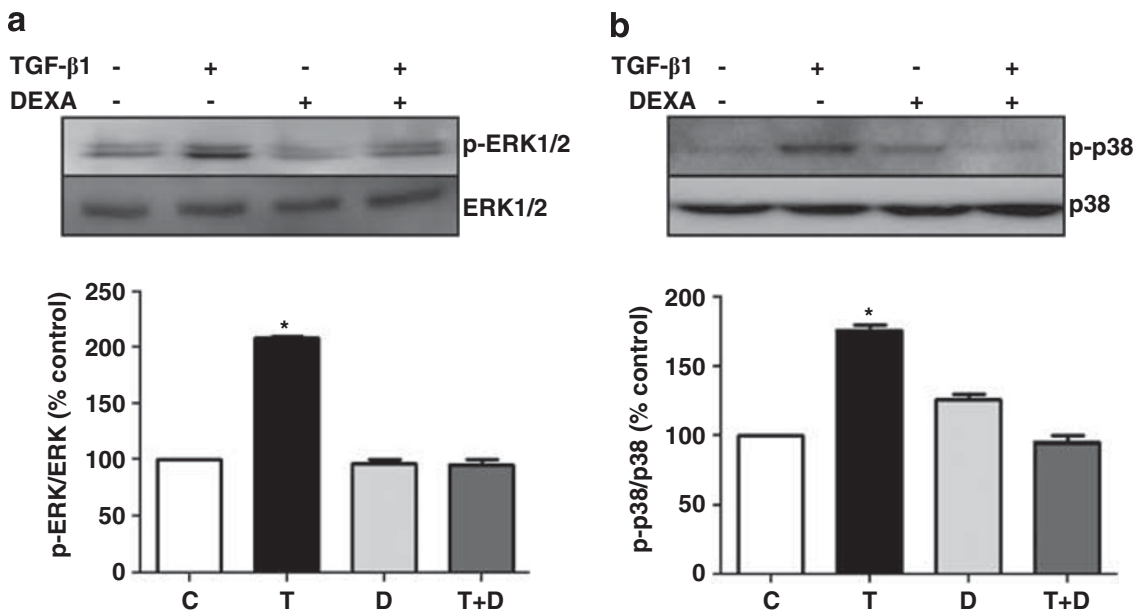

Figure 7 Effect of DEXA on the activation of ERK MAPK and p38 MAPK. DEXA inhibits the TGF- $\beta 1$-associated activation of ERK (a) and p38 MAPK (b) at 5 min. C, control; T, TGF- $\beta 1$; D, DEXA. ${ }^{*} P<0.05$ vs others.

(PD98059) and a p38 inhibitor (SB203589) blocked the TGF$\beta 1$-induced EMT (Figure 7). DEXA inhibited the phosphorylation of ERK and p38 MAPKs by TGF- $\beta 1$ stimulation (Figure 8). This finding suggests that the beneficial effect of DEXA on the EMT of the HPMCs might be mediated by an inhibition of the ERK and p38 MAPK activation induced by TGF- $\beta 1$.

\section{The Effect of DEXA on the TGF- $\beta 1$-Induced EMT is Independent of Smad 2/3 Activation}

Smad2/3 signaling is known to be responsible for the TGF$\beta 1$-induced EMT. ${ }^{17,18}$ The siRNA-mediated knockdown of Smad $2 / 3$ resulted in the restoration of the cellular phenotype of the HPMCs exposed to TGF- $\beta 1$ (Figure 9). However, DEXA did not alter TGF- $\beta 1$-induced Smad2/3 phosphor- 
ylation (Figure 10), suggesting that the effect of DEXA on the TGF- $\beta 1$-induced EMT was not mediated by the Smad $2 / 3$ pathway.

\section{DEXA Inhibits the TGF- $\beta 1$-Induced Phosphorylation of GSK-3 $\beta$ and Snail Upregulation}

TGF- $\beta 1$ induced the phosphorylation of GSK- $3 \beta$ after $3 \mathrm{~h}$ and enhanced the expression of Snail from 6 to $24 \mathrm{~h}$ (Supplementary Figure 2). DEXA ameliorated TGF- $\beta 1$-in-

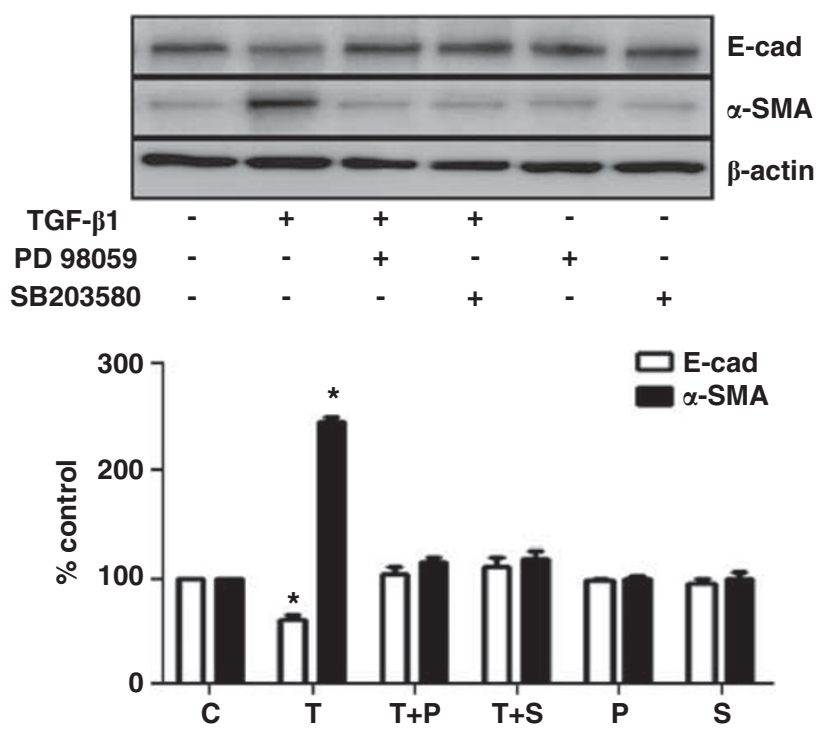

Figure 8 Effect of MAPK inhibitors on the TGF- $\beta 1$-induced EMT. An ERK inhibitor (PD98059) and a p38 inhibitor (SB203589) prevent a decrease of E-cadherin and an acquisition of $\alpha$-SMA in TGF- $\beta 1$-exposed cells at $48 \mathrm{~h}$. Representative western blot and quantitation are shown $(n=6)$. C, control; T, TGF- $\beta 1$; P, PD98059; S, SB203580. ${ }^{*} P<0.05$ vs others.
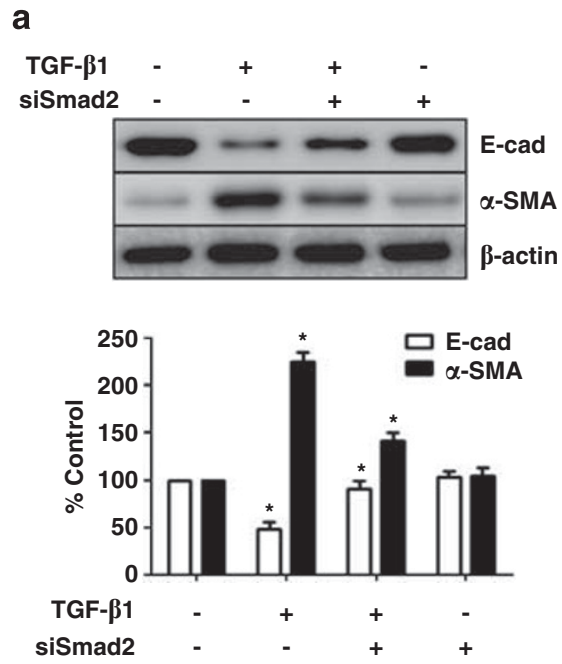

duced GSK-3 $\beta$ phosphorylation and Snail upregulation, which were blocked by RU486 (Figure 10).

\section{MAPK Inhibition Blocks GSK-3 $\beta$ Phosphorylation and Snail Upregulation}

The ERK and p38 MAPK inhibitors, PD98059 and SB 203580 , respectively, blocked the changes in GSK-3 $\beta$ phosphorylation and Snail expression in the HPMCs exposed to TGF- $\beta 1$ (Figure 11), suggesting that the activation of MAPK preceded the phosphorylation of GSK-3 $\beta$.

DEXA does not Induce a Phenotype Transition in HPFBs Although DEXA induced the MET of TGF- $\beta 1$-stimulated HPMCs, it did not alter the phenotype of the HPFBs, as assessed by morphology and the expression of mesothelial cell (E-cadherin), myofibroblast ( $\alpha$-SMA) and fibroblast (CD34 and vimentin) markers (Figure 12).

\section{DISCUSSION}

Continuous exposure to bioincompatible dialysis fluids result in peritoneal fibrosis and ultimately technical failure in $\mathrm{PD}$ patients. ${ }^{1,5,19}$ Despite several strategies to inhibit peritoneal fibrosis, including the use of antioxidants, antifibrotic cytokines, immunosuppressant or blockers of the reninangiotensin system, ${ }^{6-8}$ most of these treatments have been found to be associated with only partial protection and a limited clinical applicability. Recent studies suggest that HPMCs undergo a phenotype transition, the EMT during the $\mathrm{PD}$, which is associated with peritoneal dysfunction. ${ }^{5,20}$ Because the EMT is believed to be reversible and one of the earliest phenomena during the development of peritoneal fibrosis, EMT might be a potential therapeutic target for preserving peritoneal membrane function. ${ }^{2,21}$ In this study, we investigated the effect of DEXA on the EMT of HPMCs
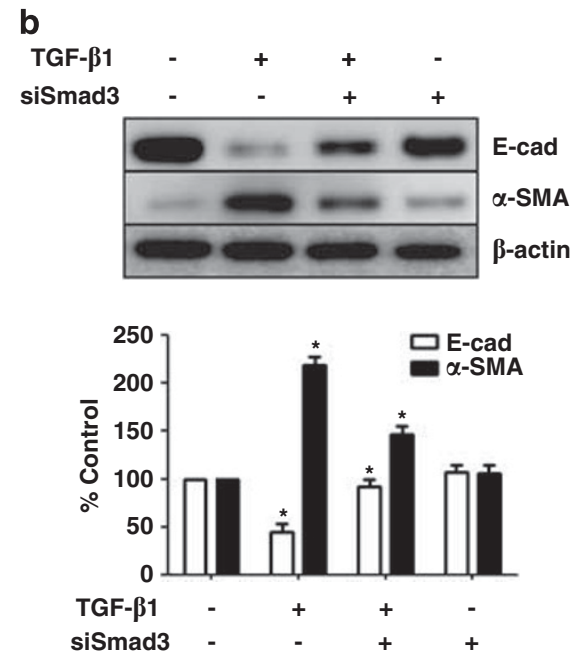

Figure 9 Effect of Smad2/3 siRNA transfection on the TGF- $\beta 1$-induced EMT. Knockdown of Smad2 (a) and Smad3 (b) in the HPMCs ameliorates the decrease of E-cadherin and the acquisition of $\alpha$-SMA in TGF- $\beta 1$-exposed cells at $48 \mathrm{~h}$. A representative western blot and quantitation are shown ( $n=6)$. ${ }^{*} P<0.05$ vs others. 

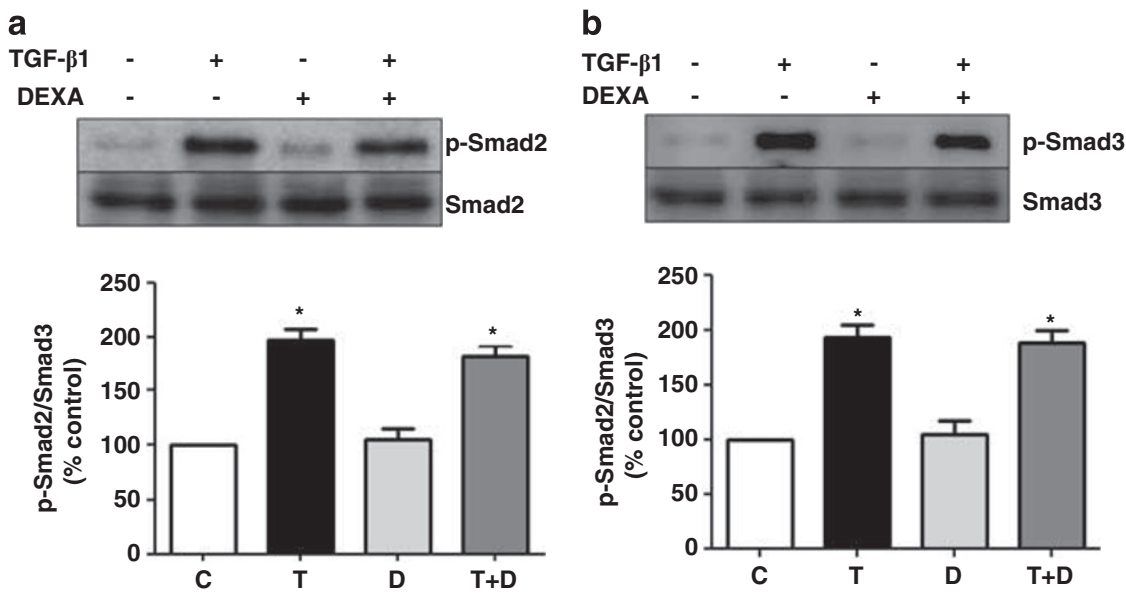

Figure 10 Effect of DEXA on TGF- $\beta 1$-associated Smad2/3 activation. TGF- $\beta 1$ phosphorylates Smad 2/3. DEXA does not inhibit the TGF- $\beta 1$-associated activation of Smad2 (a) or Smad3 (b) phosphorylation. A representative western blot and quantitation at $1 \mathrm{~h}$ are shown $(n=6)$. C, control; T, TGF- $\beta 1$; D, DEXA. ${ }^{*} P<0.05$ vs $C$ and D.
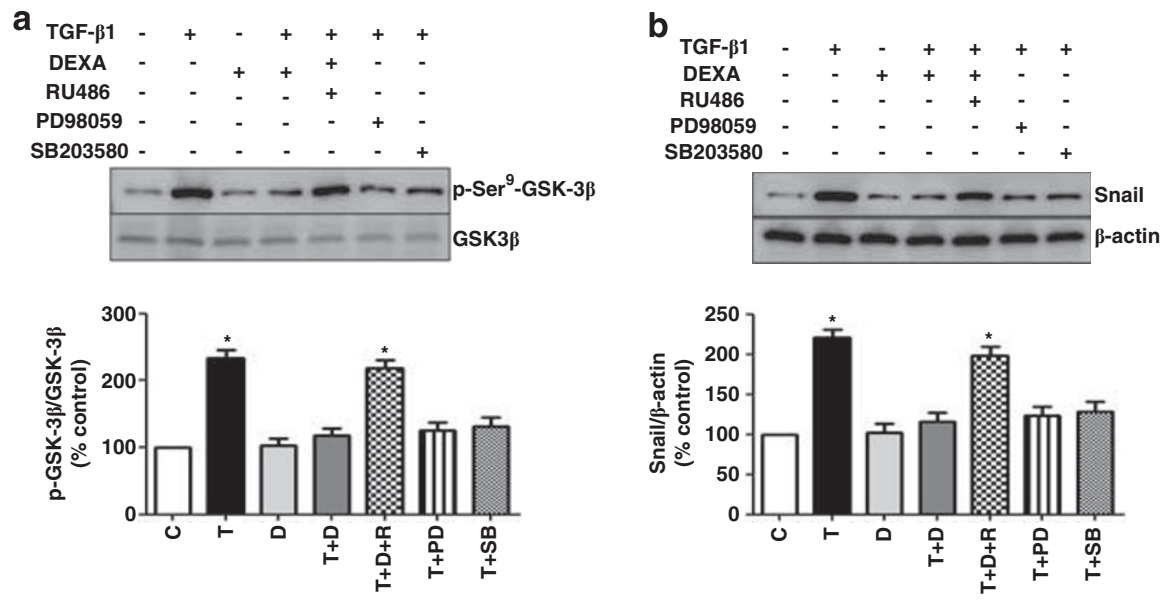

Figure 11 Effect of DEXA on GSK-3 $\beta$ phosphorylation and Snail expression. TGF- $\beta 1$ induces GSK- $3 \beta$ phosphorylation (a, $3 \mathrm{~h}$ ) and Snail upregulation (b, 6 h). DEXA ameliorates the changes in GSK-3 $\beta$ and Snail in TGF- $\beta 1$-stimulated cells, which is blocked by RU486. Both PD98059 and SB203580 also block the TGF- $\beta 1$-induced alterations of GSK-3 $\beta$ and Snail expression $(n=5)$. A representative western blot and quantitation at $1 \mathrm{~h}$ are shown $(n=6)$. C, control; T, TGF- $\beta 1$; D, DEXA; R, RU486; P, PD98059; S, SB203580. ${ }^{*} P<0.05$ vs others.

induced by TGF- $\beta 1$, a key cytokine that has a major role in the peritoneal EMT and fibrosis. Our results indicate that DEXA inhibits the EMT of HPMCs and further induces the MET of mesothelial cells during the phenotypic transition. The beneficial effects of DEXA were mediated by an inhibition of the ERK and p38 MAPK activation induced by TGF- $\beta 1$; however, the major pathway of TGF- $\beta 1$ signaling, Smad $2 / 3$, was not affected by DEXA. We have also demonstrated that DEXA ameliorates the TGF- $\beta 1$ induced upregulation of Snail, a major transcriptional repressor of E-cadherin, via the inhibition of GSK-3 $\beta$ phosphorylation.

The anti-inflammatory and immunosuppressive effects of GC are primarily mediated by the cytosolic GR, which translocates to the nucleus to regulate GC response genes. 22,23 GCs have also been demonstrated to inhibit the expression of extracellular matrix proteins, collagen and tissue inhibitors of metalloproteinases ${ }^{24}$ and to block EMT of lung epithelial cells. ${ }^{25}$ Our study also demonstrates that DEXA prevents the morphologic transition and enhanced migration of HPMCs induced by TGF- $\beta 1$, which are two characteristics of EMT. The effect of DEXA was blocked by RU486, an antagonist of the GC receptor, suggesting that DEXA ameliorates the TGF- $\beta 1$-induced EMT via the GC receptor.

The most important finding of this study is that DEXA not only inhibits the TGF- $\beta 1$-induced EMT but also induces the MET of TGF- $\beta 1$-stimulated HPMCs. DEXA improved the morphology of mesothelial cells exposed to TGF- $\beta 1$ from 

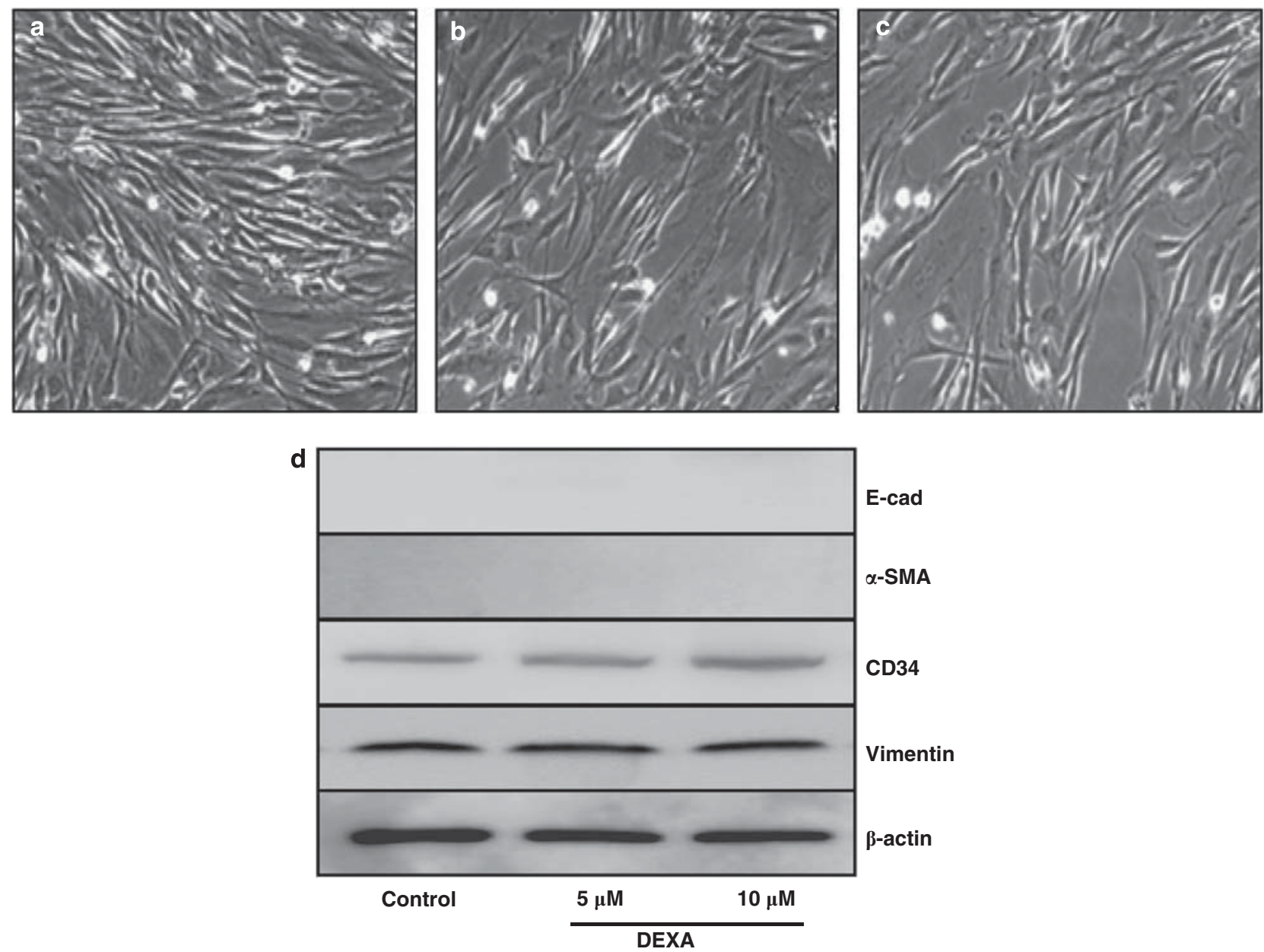

Figure 12 Effect of DEXA on the morphology of the HPFBs. Isolated HPFBs are characteristic spindle-shaped cells, (a) which is not altered by treatment with $5 \mu \mathrm{M}(\mathbf{b})$ or $10 \mu \mathrm{M}(\mathbf{c})$ DEXA (Magnification, $\times 100)$. The expression levels of mesothelial cell (E-cadherin), myofibroblast $(\alpha-S M A)$ and fibroblast (CD34 and vimentin) markers are comparable in control and DEXA-treated cells. Representative western blots are shown (d).

spindle-shaped fibroblastoid cells to a cobble stone appearance with a restoration of cell phenotype, as assessed by the expression of epithelial and mesenchymal cell markers both at the mRNA and protein levels. These observations are consistent with previous reports demonstrating the beneficial effects of steroids on postsurgical adhesion and in encapsulating peritoneal sclerosis in patients on $\mathrm{PD}$, which might be mediated by the inhibition of the inflammatory reaction and ROS production in the peritoneum. ${ }^{26-28}$ Our data lead us to propose an additional mechanism, an inhibition of the EMT and an accumulation of extracellular matrix by GCs with the potential of a restoration of cell phenotype, which would further prevent peritoneal fibrosis and accelerate healing.

TGF- $\beta$ is one of the most potent inducers of the EMT and deposition of extracellular matrix in different cell lines and animal models via an activation of complex pathways including Smads, MAPK and phosphatidylinositol 3-kinase (PI3K) pathways. ${ }^{29}$ TGF- $\beta$ is also a master molecule in the development of peritoneal fibrosis, which is demonstrated by the worsening of peritoneal function with structural damage in animals after the gene transfer of TGF- $\beta$ to the rat peritoneum. ${ }^{30-32}$ The initiation of TGF- $\beta$ signaling is launched upon the binding of TGF- $\beta$ to its cognate receptors, type I (TGFBR1) and type II (TGFRB2). This binding allows for the association and phosphorylation of receptor Smads (R-Smads), Smad2 and Smad3. Activated R-Smads then heteromerize with cytoplasmic Smad4 and, in complex, they shuttle to the nucleus to regulate gene expression. ${ }^{32}$ Although the majority of TGF- $\beta$ target genes are controlled through Smad 2/3-dependent transcriptional regulation, TGF- $\beta$ can also signal through Smadindependent pathways by activating ERK1/2, p38, c-Jun $\mathrm{N}$-terminal kinase JNK and AKT. ${ }^{32,33}$ In particular, ERK and p38 MAPK have been demonstrated to mediate Smadindependent TGF- $\beta$ responses in lung epithelial cells. ${ }^{34}$ There have been several studies demonstrating the interaction of signaling pathways between TGF- $\beta$ and GCs 
at either the transcriptional level or by protein-protein interaction. In hepatic stellate cells, GCs reduce the bioavailability of TGF- $\beta$ by transcriptional downregulation at early time points and later on by reducing TGF- $\beta$ secretion. ${ }^{35}$ DEXA also inhibits TGF- $\beta$-induced collagen II mRNA expression through ERK-integrated AP-1 activity in rat chondrocytes. ${ }^{36}$ Our study has revealed that DEXA blocks the phosphorylation of ERK and the p38 MAPK pathway in TGF- $\beta 1$-stimulated HPMCs but not the Smad2/3 pathway, suggesting the effect of DEXA on EMT via non-Smad signaling pathway in HPMCs. The mechanism by which DEXA inhibits MAPK phosphorylation appears to be mediated by a nongenomic pathway, which usually occurs within minutes or even seconds after drug administration. ${ }^{37}$ The mechanism of these nongenomic GC effects, which differs from the classical genomic model of steroid action, has not yet been fully characterized. The inhibition of MAPK using GC at early time points has already been demonstrated in several in vitro studies. ${ }^{38,39}$ The effect of DEXA on MAPK phosphorylation is abolished by RU486; however, the effect was resistant to actinomycin D, indicating a GR-dependent and transcription-independent action of DEXA. ${ }^{40}$

E-cadherin downregulation has been regarded as a marker of EMT; however, it is actually a key initial step in the transdifferentiation of epithelial cells to a mesenchymal phenotype. ${ }^{41,42}$ E-cadherin expression is a hallmark of a fully differentiated epithelium. E-cadherin functions to maintain cell-cell junctions and, thereby, inhibits aberrant cell proliferation and migration. Indeed, the loss of E-cadherin function via siRNA-mediated knockdown results in the loss of cell contacts and cell scattering along with the acquisition of an elongated, fibroblastic morphology in mammary epithelial cells. ${ }^{42}$ This finding suggests that a loss of E-cadherin is not just one of the manifestations of the EMT program but that E-cadherin itself acts as a pleiotropic regulator of the cell's phenotype, enabling it to function as a master regulator of cell behavior. In this study, MAPK activation was the earliest phenomenon in the TGF- $\beta 1$-induced EMT of the HPMCs, which stimulated GSK-3 $\beta$ phosphorylation and the inhibition of Snail degradation, E-cadherin downregulation and the EMT. GSK3- $\beta$ is a master regulator of cell adhesion stability via the degradation of the Snail family of transcriptional repressors (Snail and Slug) of E-cadherin. ${ }^{14}$ Interestingly, TGF- $\beta 1$-induced GSK3- $\beta$ phosphorylation was inhibited by both DEXA and MAPK inhibitors, indicating that MAPK activation precedes via GSK3- $\beta$ phosphorylation in TGF- $\beta$-stimulated HPMCs (Figure 13). The signaling pathways responsible for Smad2/3mediated E-cadherin downregulation were not investigated in this study as DEXA did not affect Smad2/3 signaling in HPMCs.

A limitation of this study is the in vitro character of the data and that there is no validation of the effect of DEXA using an animal model of PD. General caveats of an in vitro

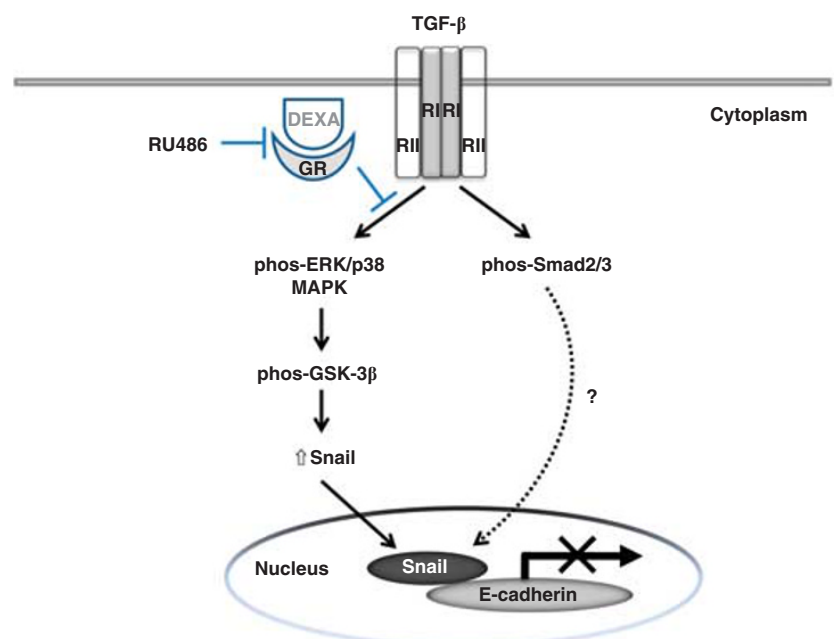

Figure 13 Proposed pathway for the effect of DEXA on the TGF- $\beta 1$ induced EMT in HPMCs. TGF- $\beta 1$ leads to the EMT via the MAPK and Smad2/3-dependent pathways. MAPK phosphorylation induces the inactivation of GSK-3 $\beta$ by phosphorylation, which results in the inhibition of Snail degradation. Snail upregulation in TGF- $\beta 1$-stimulated HPMCs induces the transcriptional repression of E-cadherin and the EMT. DEXA ameliorates the EMT by the inhibition of ERK/p38 MAPK phosphorylation via GR. The dephosphorylation of MAPK and GSK-3 $\beta$ by DEXA restores the normal degradation of Snail, which ameliorates E-cadherin downregulation by TGF- $\beta 1$. DEXA did not affect TGF- $\beta 1$-induced Smad2/3 phosphorylation in the HPMCs.

experiment such as the elimination of interactions among different cell types and hemodynamic influences should be considered in interpreting the results. Nonetheless, mesothelial cells are a major population of peritoneal cells and are known to have a key role in the development of peritoneal fibrosis. ${ }^{1,2}$ Therefore, we still need to understand the isolated effects of DEXA on mesothelial cells which are demonstrated in this study.

Although the beneficial effect of DEXA on the EMT and a therapeutic potential for organ fibrosis were demonstrated by this study, the long-term use of GCs at a significant dose is known to promote fibrosis, especially in the kidney. ${ }^{12,43}$ DEXA increases the expression of connective tissue growth factor, a strong enhancer of renal fibrosis, and PAI-1 expression in human proximal renal tubular cells. ${ }^{43}$ These findings suggest that GCs, which act as anti-inflammatory or antifibrotic agents, can operate as profibrotic factors in a dose- and time-dependent manner. Further studies will be necessary to define the role of GC during the EMT and in peritoneal fibrosis in terms of the dose and duration of treatment.

In conclusion, this study demonstrates that DEXA protects mesothelial cells from phenotypic transition and further induces the MET of mesothelial cells during their phenotypic transition. The beneficial effect of DEXA on the peritoneal EMT is mediated through the dephosphorylation of ERK and p38 MAPK and is associated with 
the activation of GSK-3 $\beta$ and Snail repression in TGF- $\beta 1$ stimulated HPMCs. This is the first study addressing the role of GC on the TGF- $\beta 1$-induced EMT and MET of HPMCs with an elucidation of potential mechanisms by which GC regulates the EMT through different signal transduction pathways.

Supplementary Information accompanies the paper on the Laboratory Investigation website (http://www.laboratoryinvestigation.org)

\section{ACKNOWLEDGEMENTS}

This study was supported by a grant of the Korea Healthcare Technology R\&D Project, Ministry for Health \& Welfare, Republic of Korea (A100422).

\section{DISCLOSURE/CONFLICT OF INTEREST}

The authors declare no conflict of interest.

1. Aroeira LS, Aguilera A, Sanchez-Tomero JA, et al. Epithelial to mesenchymal transition and peritoneal membrane failure in peritoneal dialysis patients: pathologic significance and potential therapeutic interventions. J Am Soc Nephrol 2007;18:2004-2013.

2. Yanez-Mo M, Lara-Pezzi E, Selgas $R$, et al. Peritoneal dialysis and epithelial-to-mesenchymal transition of mesothelial cells. New Engl J Med 2003;348:403-413.

3. Thiery JP. Epithelial-mesenchymal transitions in tumour progression. Nat Rev Cancer 2002;2:442-454.

4. Kalluri R, Weinberg RA. The basics of epithelial-mesenchymal transition. J Clin Invest 2009;119:1420-1428.

5. Selgas R, Bajo A, Jimenez-Heffernan JA, et al. Epithelial-to-mesenchymal transition of the mesothelial cell-its role in the response of the peritoneum to dialysis. Nephrol Dial Transplant 2006;21(Suppl 2): ii2-ii7.

6. Yu MA, Shin KS, Kim JH, et al. HGF and BMP-7 ameliorate high glucoseinduced epithelial-to-mesenchymal transition of peritoneal mesothelium. J Am Soc Nephrol 2009;20:567-581.

7. Aguilera A, Aroeira LS, Ramirez-Huesca $M$, et al. Effects of rapamycin on the epithelial-to-mesenchymal transition of human peritoneal mesothelial cells. Int J Artif Organs 2005;28:164-169.

8. Bajo MA, Perez-Lozano ML, Albar-Vizcaino $P$, et al. Low-GDP peritoneal dialysis fluid ('balance') has less impact in vitro and ex vivo on epithelial-to-mesenchymal transition (EMT) of mesothelial cells than a standard fluid. Nephrol Dial Transplant 2011; 26:282-291.

9. Evans RM. The steroid and thyroid hormone receptor superfamily Science 1988:240:889-895.

10. Bledsoe RK, Montana VG, Stanley TB, et al. Crystal structure of the glucocorticoid receptor ligand binding domain reveals a novel mode of receptor dimerization and coactivator recognition. Cell 2002; 110:93-105.

11. Godoy P, Lakkapamu S, Schug M, et al. Dexamethasone-dependent versus -independent markers of epithelial to mesenchymal transition in primary hepatocytes. Biol Chem 2010;391:73-83.

12. Kimura $\mathrm{H}$, Li X, Torii K, et al. Glucocorticoid enhances hypoxia- and/or transforming growth factor-beta-induced plasminogen activator inhibitor-1 production in human proximal renal tubular cells. Clin Exp Nephrol 2011;15:34-40.

13. Birchmeier W. Cell adhesion and signal transduction in cancer. EMBO Rep 2005;6:413-417.

14. Zhou Binhua P., Deng Jiong, Xia Weiya, et al. Dual regulation of Snail by GSK-3 $\beta$-mediated phosphorylation in control of epithelialmesenchymal transition. Nat Cell Biol 2004;6:931-940.

15. Witowski J, Jörres A. Peritoneal cell culture: fibroblasts. Perit Dial Int 2006;26:292-299.

16. Kim SH, Yu MA, Ryu ES, et al. Indoxyl sulfate-induced epithelial-tomesenchymal transition and apoptosis of renal tubular cells as novel mechanisms of progression of renal disease. Lab Invest 2012;92: 488-498.
17. Kolosova I, Nethery D, Kern JA. Role of Smad2/3 and p38 MAP kinase in TGF- $\beta 1$-induced epithelial-mesenchymal transition of pulmonary epithelial cells. J Cell Physiol 2011;226:1248-1254.

18. Li Y, Zhang J, Fang L, et al. Lefty A attenuates the TGF-beta1-induced epithelial to mesenchymal transition of human renal proximal epithelial tubular cells. Mol Cell Biochem 2010;339:263-270.

19. Vargha $\mathrm{R}$, Endemann $\mathrm{M}$, Kratochwill $\mathrm{K}$, et al. Ex vivo reversal of in vivo transdifferentiation in mesothelial cells grown from peritoneal dialysate effluents. Nephrol Dial Transplant 2006;21: 2943-2947.

20. Aroeira LS, Aguilera A, Selgas R, et al. Mesenchymal conversion of mesothelial cells as a mechanism responsible for high solute transport rate in peritoneal dialysis: role of vascular endothelial growth factor. Am J Kidney Dis 2005;46:938-948.

21. Lee $\mathrm{HB}, \mathrm{HaH}$. Mechanisms of epithelial-mesenchymal transition of peritoneal mesothelial cells during peritoneal dialysis. J Korean Med Sci 2007;22:943-945.

22. Barnes PJ, Adcock IM. Glucocorticoid resistance in inflammatory diseases. Lancet 2009;373:1905-1917.

23. Nicolaides NC, Galata Z, Kino T, et al. The human glucocorticoid receptor: molecular basis of biologic function. Steroids 2010;75: $1-12$.

24. Guller $S$, Wozniak R, Kong $L$, et al. Reduction of extracellular matrix protein expression in human amnion epithelial cells by glucocorticoids: a potential role in preterm rupture of the fetal membranes. J Clin Endocrinol Metab 1995;80:3273-3278.

25. Zhang L, Lei W, Wang $X$, et al. Glucocorticoid induces mesenchymalto-epithelial transition and inhibits TGF- $\beta 1$-induced epithelial-tomesenchymal transition and cell migration. FEBS Lett 2010;584: 4646-4654.

26. Courtney AE, Doherty CC. Single-center experience of encapsulating peritoneal sclerosis in patients on peritoneal dialysis for end-stage renal failure. Kidney Int 2006:69:1094.

27. Lafrance JP, Letourneau I, Ouimet D, et al. Successful treatment of encapsulating peritoneal sclerosis with immunosuppressive therapy. Am J Kidney Dis 2008;51:e7-10.

28. Goulding NJ, Euzger HS, Butt SK, et al. Novel pathways for glucocorticoid effects on neutrophils in chronic inflammation. Inflamm Res 1998;47(Suppl 3):S158-S165.

29. Xu J, Lamouille S, Derynck R. TGF-beta-induced epithelial to mesenchymal transition. Cell Res 2009;19:156-172.

30. Margetts PJ, Kolb M, Galt T, et al. Gene transfer of transforming growth factor-beta 1 to the rat peritoneum: effects on membrane function. J Am Soc Nephrol 2001;12:2029-2039.

31. Margetts PJ, Bonniaud P, Liu L, et al. Transient overexpression of TGF- $\beta 1$ induces epithelial mesenchymal transition in the rodent peritoneum. J Am Soc Nephrol 2005;16:425-436.

32. Patel $\mathrm{P}$, Sekiguchi $\mathrm{Y}$, Oh KH, et al. Smad3-dependent and -independent pathways are involved in peritoneal membrane injury. Kidney Int 2010;77:319-328.

33. Lan HY, Chung AC. Transforming growth factor- $\beta$ and Smads. Contrib Nephrol 2011;170:75-82.

34. Willis BC, Borok Z. TGF-beta-induced EMT mechanisms and implications for fibrotic lung disease. Am J Physiol Lung Cell Mol Physiol 2007;293:525-534.

35. Bolkenius U, Hahn D, Gressner AM, et al. Glucocorticoids decrease the bioavailability of TGF-beta which leads to a reduced TGF-beta signaling in hepatic stellate cells. Biochem Biophys Res Commun 2004;325:1264-1270.

36. Miyazaki $Y$, Tsukazaki T, Hirota $Y$, et al. Dexamethasone inhibition of TGF beta-induced cell growth and type II collagen mRNA expression through ERK-integrated AP-1 activity in cultured rat articular chondrocytes. Osteoarthritis Cartilage 2000;8:378-385.

37. Stellato C. Post-transcriptional and nongenomic effects of glucocorticoids. Proc Am Thorac Soc 2004;1:255-263.

38. Kassel O, Sancono A, Kratzschmar J, et al. Glucocorticoids inhibit MAP kinase via increased expression and decreased degradation of MKP-1. EMBO J 2001;20:7108-7116.

39. Engelbrecht $\mathrm{Y}$, de Wet $\mathrm{H}$, Horsch $\mathrm{K}$, et al. Glucocorticoids induce rapid up-regulation of mitogen-activated protein kinase phosphatase- 1 and dephosphorylation of extracellular signal-regulated kinase and impair proliferation in human and mouse osteoblast cell lines. Endocrinology 2003;144:412-422. 
40. Hafezi-Moghadam A, Simoncini T, Yang E, et al. Acute cardiovascular protective effects of corticosteroids are mediated by nontranscriptional activation of endothelial nitric oxide synthase. Nat Med 2002;8:473-479.

41. Onder TT, Gupta PB, Mani SA, et al. Loss of E-Cadherin promotes metastasis via multiple downstream transcriptional pathways. Cancer Res 2008;68:3645-3654.
42. Wendt MK, Taylor MA, Schiemann BJ, et al. Down-regulation of epithelial cadherin is required to initiate metastatic outgrowth of breast cancer. Mol Biol Cell 2011;22:2423-2435.

43. Kimura H, Li X, Torii K, et al. Dexamethasone enhances basal and TNFalpha-stimulated production of PAl-1 via the glucocorticoid receptor regardless of 11 beta-hydroxysteroid dehydrogenase 2 status in human proximal renal tubular cells. Nephrol Dial Transplant 2009;24:1759-1765. 